
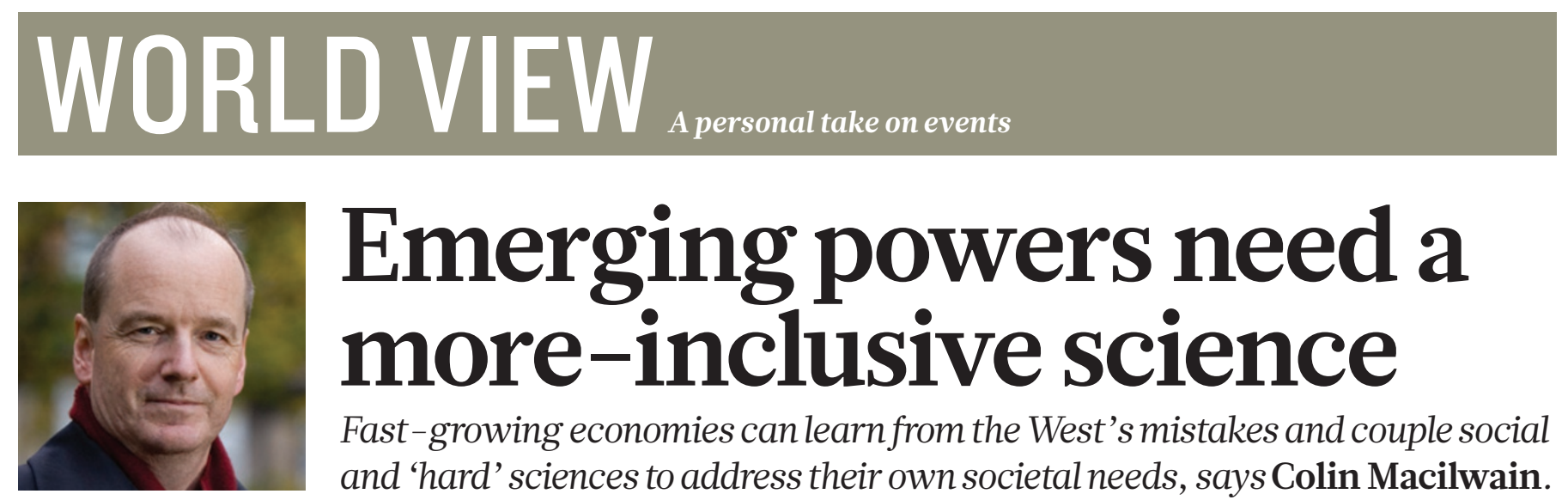

\title{
Emerging powers need a more-inclusive science
}

Fast-growing economies can learn from the West's mistakes and couple social and 'hard' sciences to address their own societal needs, says Colin Macilwain.

$\mathrm{R}$ io de Janeiro's peerless Copacabana beach has not changed much in the 15 years since I last visited, but there has been one innovation: all along the promenade, sturdy, open-air gym facilities invite locals and tourists alike to indulge in a little anaerobic exercise.

This free equipment seems an obvious approach to improving public health. But tell that to inhabitants of the Bronx in New York or of London's East End, where the most visible signs of health science are the nearby glass towers in Washington Heights or Whitechapel, in which biologists develop drugs that largely benefit the well-to-do.

Rio's outdoor gyms reflect the work of researchers such as epidemiologist Pedro Hallal at the Federal University of Pelotas in southern Brazil, who is part of an influential movement to better understand the links between mothers' health, early-childhood exercise and lifelong health outcomes. This is the sort of societal research that the developing world needs as it expands its scientific influence.

"Let's forge this connection between the social science and the hard sciences," Michel Temer, vice-president of Brazil, told the 6th World Science Forum in Rio de Janeiro - the reason for my visit in November. The point was forcefully reiterated by Linxiu Zhang of the Chinese Academy of Sciences, and many other speakers.

Make no mistake: the geographical balance of power in global science is shifting. China has surpassed the United States as the world's largest PhD factory (see Nature 472, 276-279; 2011) and about now, according to a 2011 report by Britain's Royal Society, it is scheduled to surpass the US volume of scientific literature in research journals. Brazil awarded 14,000 PhDs last year.

The shift is accompanied by real political determination from the emerging powers to couple the social sciences with 'hard' science and engineering to address society's needs. For their own pressing political reasons, the leaders of Brazil, China and other fast-growing economies need answers to mounting societal problems - water, food, health, energy and climate change, for example. That is not the case in the United States or Europe, where leaders' priorities are short-term and financial, and science is arranged to suit various stakeholders - notably firms that supply drugs and military equipment - as well as the needs of scientists themselves and their universities.

There are well-charted historical reasons for the West's narrow view of what constitutes science. Around 1900, scientists of the Royal Society of London distanced themselves from colleagues in the humanities (leading to the formation of the British Academy), and the US National Academy of Sciences followed the same path.

The outcome has been subtler in mainland

\section{NATURE.CON}

Discuss this article online at:

go.nature.com/af8erx
Europe. The German word for science, Wissenschaft, acknowledges a wider body of knowledge than just the natural sciences, for example; and the former president of the prestigious European Research Council, Helga Nowotny, is a sociologist.

Yet the question of fair treatment for the social sciences is dogging the new European Union (EU) research programme Horizon 2020, the largest in the world outside the United States. Social scientists feel that they have been locked out of the drafting of the Horizon 2020 work programmes. At a 26 November meeting in Brussels on 'smart cities', for example, speakers castigated the planned programme for concentrating on technology-led pilots, even though the real roadblock is how people use the technologies we already have.

These are not abstract, philosophical questions: quantitative behavioural research could readily fill knowledge gaps and design processes that would enable people to better manage their energy use, for example. But it does not happen because EU research programmes are also designed around the needs of stakeholders: in this case, device manufacturers, power companies and university scientists and engineers who know the ropes from previous programmes.

Another closely associated issue raised at the Rio meeting is the fact that global science still has a huge problem with research 'silos', in which researchers are obliged to operate within insular, sometimes archaic disciplines. This was broached by physicist Luiz Davidovich, a director of the Brazilian Academy of Sciences in Rio, who called for the "reformulation of the university, towards interaction between disciplines". But the West's funding agencies and universities - as well as its publishing industry - are all set up in ways that have persistently stymied such change. An opportunity surely exists for emerging scientific powers to do things differently as they grow, by building an interdisciplinary outlook into their structures.

The World Science Forum is just one instrument that is attempting to address such problems. In 2012, the Global Research Council was created at the instigation of Subra Suresh, then director of the US National Science Foundation, as a vehicle for the wider governance of science.

Existing worldwide organizations have limited influence, however. The new global agenda is more likely to be driven by the most powerful of the emerging powers: China, in particular, but also Brazil, India, South Korea and South Africa. That group of emerging nations has the opportunity, right now, to build a science that will serve not just the interests of national oligarchies, or of researchers themselves, but of society at large.
Colin Macilwain writes about science policy from Edinburgh, UK. e-mail:cfmworldview@googlemail.com 